\title{
The high-performance machining of the curved surfaces with the progressive cutting geometry of the end mill
}

\author{
Alexander Khramov ${ }^{1}$, Evgeniy Kiselev, ${ }^{2, *}$, and Evgeniy Leksin ${ }^{1}$ \\ ${ }^{1}$ Haltec Ltd, 432071 Ulyanovsk, Russia \\ ${ }^{2}$ Ulyanovsk State Technical University, 432027 Ulyanovsk, Russia
}

\begin{abstract}
There are some results of practical application of the solid carbide end mill developed in HALTEC Ltd company, using for high-performance machining of curved surfaces of workpieces, which have a complex spatial form. It's shown how to get high-performance machining of curved surfaces with a multidirectional curvature in heat-treatable and high strength $\mathrm{Ti}$ alloy $\mathrm{Ti}-6 \mathrm{Al}-2 \mathrm{Sn}-2 \mathrm{Zr}-2 \mathrm{Mo}-2 \mathrm{Cr}-0.15 \mathrm{Si}$ [Ti6-22-22]. The real experience of the implementation of proposed end mill in the technological process of compressor blade machining is described.
\end{abstract}

\section{Introduction}

The machining of non-rigid workpieces, which have relatively small volume in large dimensions is a difficult task, which facing engineering technology at the moment. Due to the high ductility of technological system the high-performance machining of this workpieces usually impossible. Occurring in the surface layer of the treated parts after its removal from the machine residual stresses are the result of thermal and power intensity of the cutting, which is especially critical for non-rigid parts. Therefore, in practice, specialists are try to avoid high temperatures and cutting forces in the contact zone of the tool and the workpiece by reducing elements of the cutting conditions.

The most of non-rigid parts which used in the aircraft industry, have a complex spatial shape, including curved sections which are processed by milling on the multiaxis CNC machines. Their machining is carried out by end mills with spherical or toroidal end face, the choice each time determined by the capabilities of the equipment, the rigidity of the technological system, the geometric parameters of the specific milling, economic feasibility, etc. The main factor which is limiting the machining performance and, consequently, the cost of the final product is the small width of the cut, which affects the height of scallops machined surface. Obviously, for lowest roughness of the machined surface is important to have the more efficient radius of contact of the tool and workpiece, small step between two successive passages and minimum level of runout of tool.

But with a decrease of the step the machining time substantially increases. At the same time increase of the effective radius is currently achieved by using larger end mill diameter what is respectively increases the radius of spherical section or radius of the torus. It is known that the minimum roughness of the machined surface is achieved by the use of solid carbide end mills, but the use of such tools with a diameter bigger than $32 \mathrm{~mm}$ is not economically feasible due to their high cost.

Thus, all the cutting elements of the end mill (with ball or toroidal end face) - radius, end face and peripheral teeth may take part in cutting, although it should be noted that the machining of complex curved surfaces where depth of cut is relatively small, only radius of end mill is participates in cutting.

Thus, the development of the end mill, which combines the advantages of spherical and toroidalshaped end and capable of leading high-performance machining of non-rigid parts is an urgent task.

The new end mill which combines two curved area $R_{B}$ and $R_{T}$ and $R_{B}>R_{S H A N K}$ and was developed in HALTEC Ltd (Ulyanovsk, Russia) is shown on Fig. 1 and 2. This end face design can significantly increase the effective diameter of the contact between end mill and workpiece, thereby significantly increasing the spacing between successive passes for high productivity.

A distinctive feature of the proposed end mill is the presence of the flat section $W$ which is perpendicular to the axis of rotation (Wiper) and further cuts the scallops after consecutive passes. Sandvik Coromant (Sweden) was the first company who was using Wiper technology for machining for turning inserts T-max series. It's known that the use of inserts with Wiper geometry allows for doubling the feed while maintaining highaltitude surface roughness or halve these parameters while maintaining feed [1]. Later skills with turning inserts with Wiper geometry were extended to the milling inserts. Also tool companies invited to install the additional wiper insert on the cutter.

\footnotetext{
* Corresponding author: kec.ulstu@mail.ru
} 


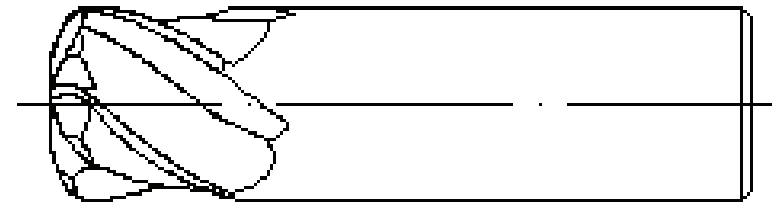

Fig. 1. General view of the proposed end mill.

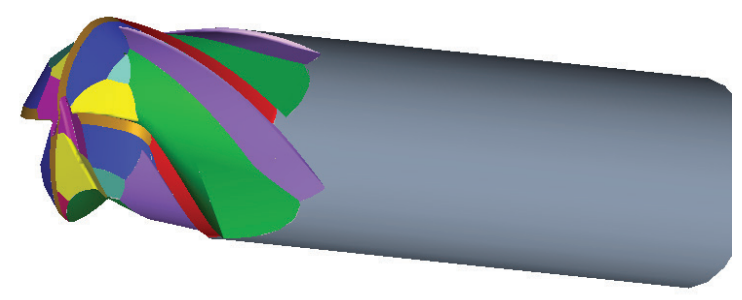

Fig. 2. 3D model of the proposed end mill in the window of WALTER Helitronic Tool Studio software.

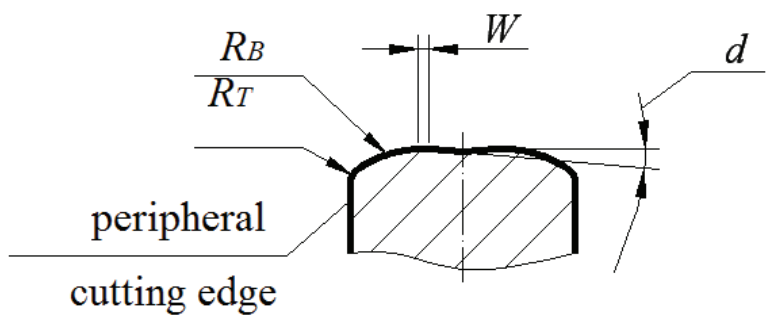

Fig. 3, a. Variant of end mill 1.

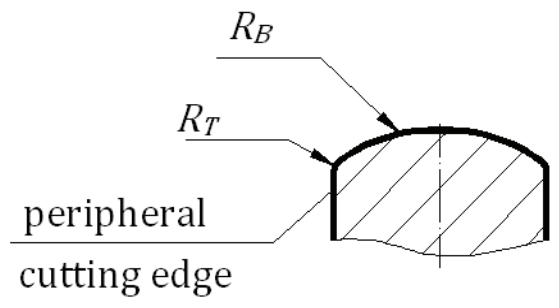

Fig. 3, b. Variant of end mill 2.

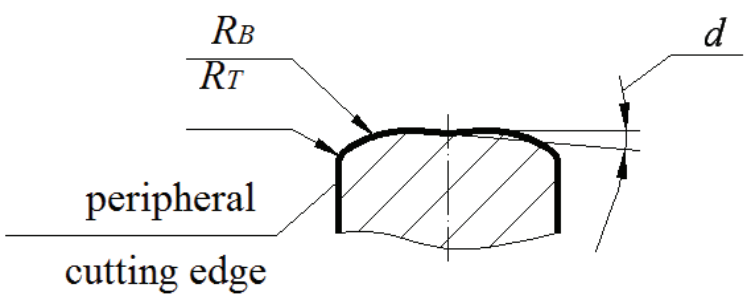

Fig. 3, c. Variant of end mill 3.

Wiper application section on the solid carbide tool is performed for the first time.

Furthermore, proposed end mill has a dish angle $d$ to prevent friction of the end face teeth and machining surface.

Thus, in general case, the proposed mill is characterized by two radius sections $\mathrm{R}_{\mathrm{B}}$ and $\mathrm{R}_{\mathrm{T}}$, the flat section $W$ and dish angle $d$ (Fig. 3a-c) [2].

\section{Results}

The basic ability to cut curvilinear surfaces of the workpiece on the example of milling titanium alloy Ti-622-22 is shown on Fig. 4 a) and b). Essence of the test is the milling of a curved convex and concave surface by the end face of tool. The workpiece was fixed in machine grip SCHUNK KSG125 and was machined with using of typical end mill (series MT4RXA, cutting diameter $\mathrm{D}=20 \mathrm{~mm}$, corner radius $\mathrm{Rt}=3 \mathrm{~mm}$, cutting length Lcut $=38 \mathrm{~mm}$ ) and also with using of HALTEC proposed end mill (series MI4RXA, type 1, the cutting diameter $\mathrm{D}=20 \mathrm{~mm}$, corner radius $\mathrm{Rtor}=3 \mathrm{~mm}$, ball section radius $\mathrm{Rb}=15 \mathrm{~mm}$, Wiper area $=0,1 \mathrm{~mm}$, cutting length Lcut $=38 \mathrm{~mm}$ ).

Practical recommendations how to use the proposed end mill for machining are shown in Table.

Table 1. Recommendations for use of the proposed end mill series MT4DXA

\begin{tabular}{|l|c|c|c|}
\hline \multirow{2}{*}{ Type of machining } & \multicolumn{3}{|c|}{$\begin{array}{c}\text { Variant of end mill } \\
\text { from Fig. 3 }\end{array}$} \\
\cline { 2 - 4 } & 1 & 2 & 3 \\
\hline $\begin{array}{l}\text { Rough curved surfaces } \\
\text { milling }\end{array}$ & 0 & + & + \\
\hline Rough plane milling & + & 0 & + \\
\hline $\begin{array}{l}\text { Finish curved surfaces } \\
\text { milling }\end{array}$ & - & + & + \\
\hline Finish plane milling & + & - & - \\
\hline $\begin{array}{l}\text { Slot milling, pocket } \\
\text { milling }\end{array}$ & + & - & 0 \\
\hline $\begin{array}{l}\text { Milling by the peripheral } \\
\text { teeth }\end{array}$ & 0 & 0 & 0 \\
\hline
\end{tabular}

$\langle+\rangle-$ recommended; $\langle 0 »-$ permissible; $«-»-$ not recommended

Cutting conditions: depth of cut ap $=1.7 \mathrm{~mm}$; width of cut ae $=7 \mathrm{~mm}$; cutting speed $\mathrm{Vc}=40 \mathrm{~m} / \mathrm{min}$; feed per tooth $\mathrm{fz}=0,5 \mathrm{~mm}$.

Typical end mill was broken after 6 minutes of machining (Fig 5, a). Proposed end mill kept possibility to work after 2 hours (Fig. 5, b)

In addition, the power intensity of the cutting by proposed end mill is about $40 \%$ lower than the typical end mill (Fig. 6).

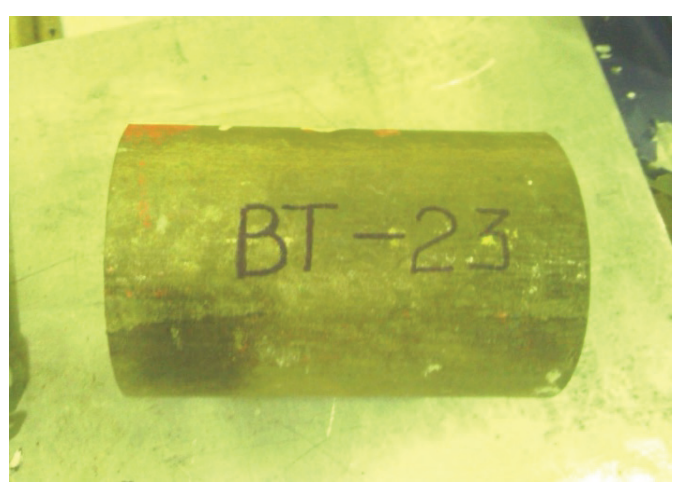

Fig. 4, a. Test piece. 


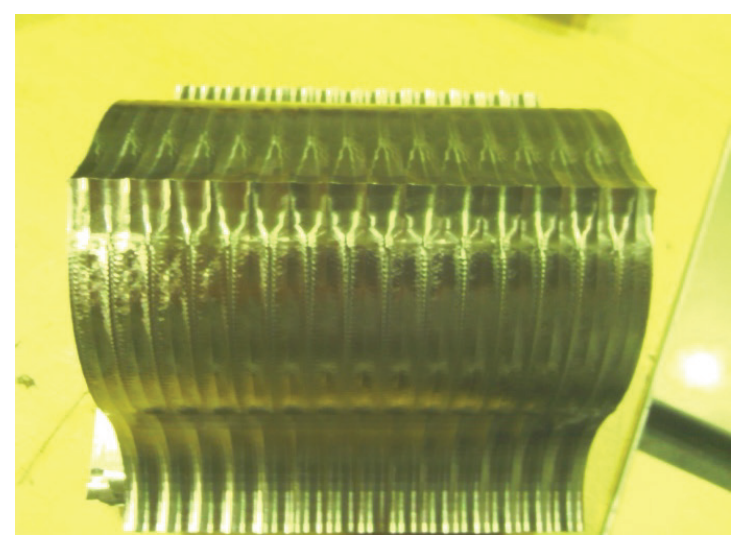

Fig. 4, b. Test piece after machining by proposed end mill.

The practical value of proposed end mill is the possibility of a significant increase of blade machining performance.

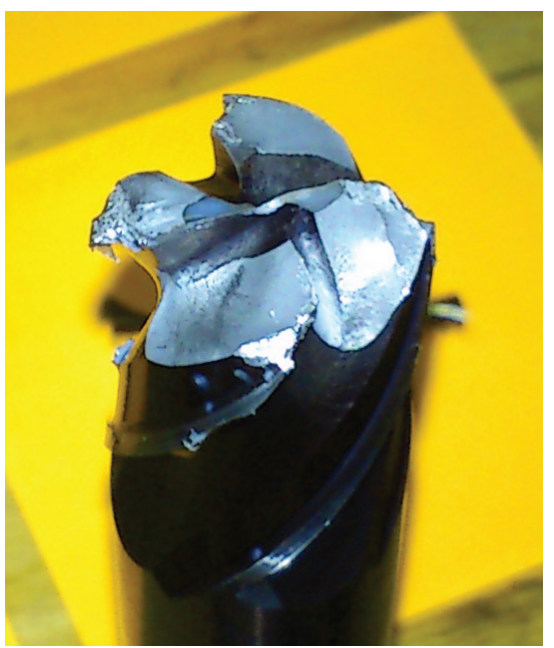

Fig. 5, a. Typical end mill series MT4RXA after 20 minutes machining of the test piece

The aim is to achieve maximum performance with satisfactory quality of machined surface and tool life for milling operation profile of the blade of compressor turbine engines. Used workpiece is stamping of titanium alloy TiAl6V with $2 \mathrm{~mm}$ allowance on each side.

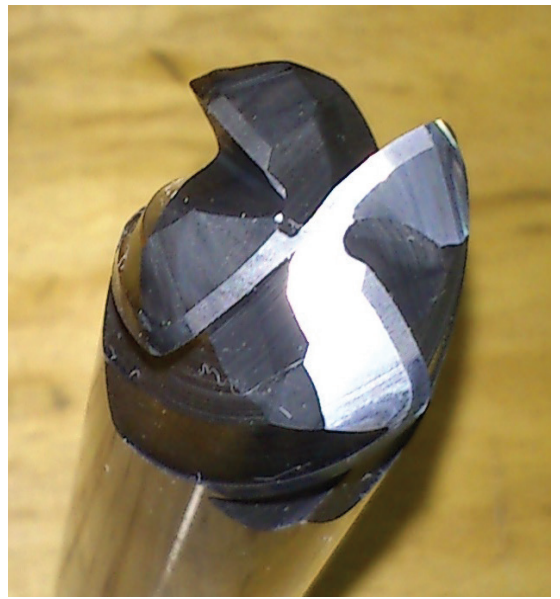

Fig. 5, b. Proposed end mill series MT4DXA after 120 minutes machining of the test piece.

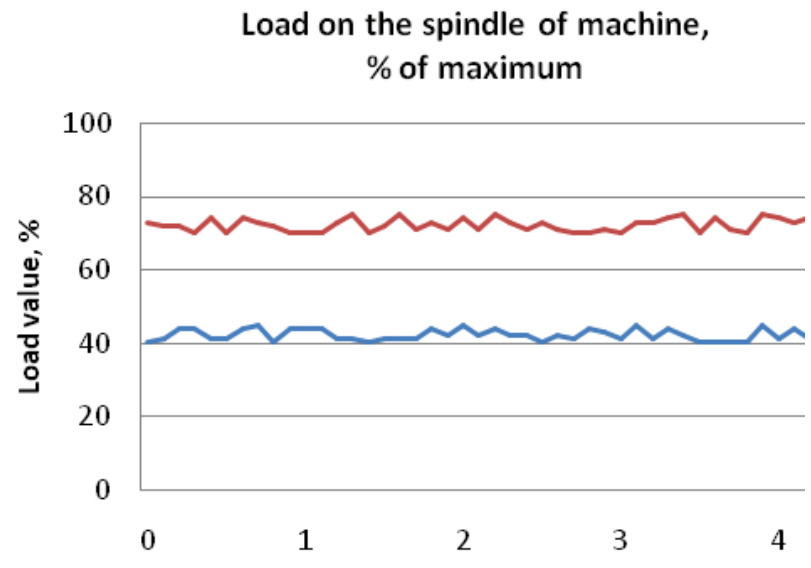

Fig. 6. Specific power intensity of the milling of the test piece. The time interval of 4 seconds is shown (steady cutting).

Workpiece clamping is carried out for the pre-treated surface of the blade lock in a specially designed device which is mounted on the faceplate, clamped in a selfcentering three-jaw chuck of the MAZAK Integrex i-200 machining center. From the side of the shank the workpiece is pressed rear center with a force of $200 \mathrm{~N}$ (Fig. 7).

According to the accepted and proven technology, it is necessary to leave allowance for subsequent finish milling of $0.3 \mathrm{~mm}$.

The modern technological process of machining of similar parts uses semi-finishing and finishing five-axis milling in one setup. According to the results of the used NC-program the semi-finishing blade machining carried by toroidal end mill series MT4RXA, described earlier. Cutting conditions for reasonable tool life with satisfactory surface quality are: cutting speed $\mathrm{Vc}=$ $40 \mathrm{~m} / \mathrm{min}$; feed per tooth $\mathrm{fz}=0,06 \mathrm{~mm}$; depth of cut ap $=$ $2 \mathrm{~mm}$; width of cut ae $=3 \mathrm{~mm}$. Under such conditions, the machining time of semi-finishing blade profile operation was 27 minutes. Tool life until $0.3 \mathrm{~mm}$ flank wear is 108 minutes or four parts.

Exterior view of the workpiece after semi-finishing blade milling is shown in Fig. 8.

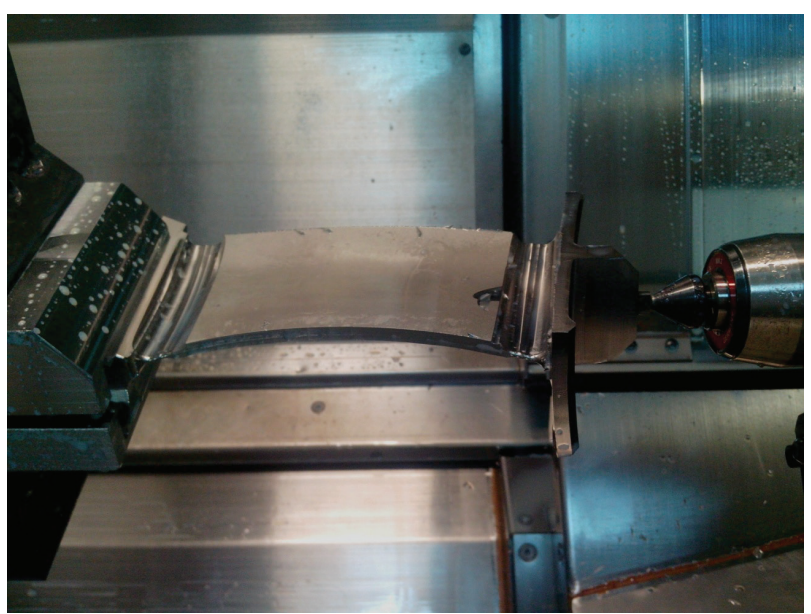

Fig. 7. Blade workpiece in the machine device. 


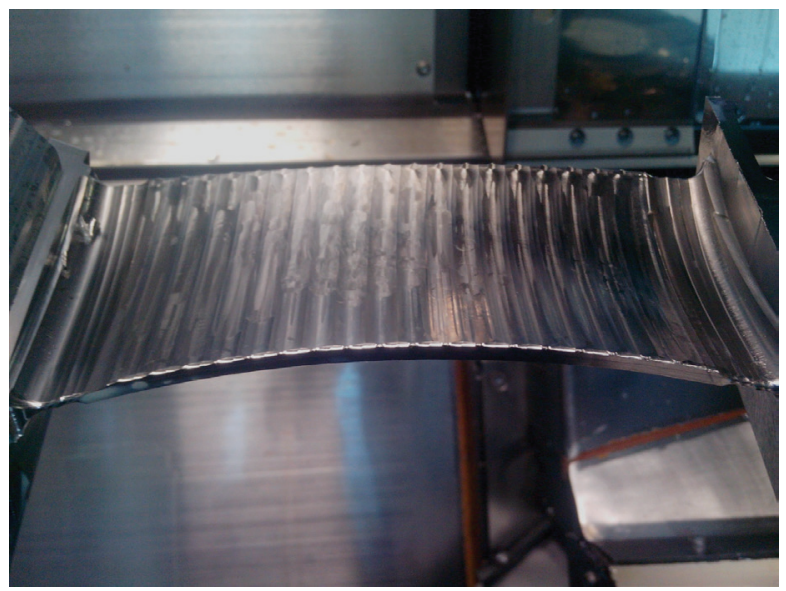

Fig. 8. Exterior view of the workpiece after semi-finishing blade milling.

Using of own proposed original end mill allowed to increase the feed more than 3 times - up to $0.2 \mathrm{~mm} /$ tooth with increasing the cutting width from 3 to $7 \mathrm{~mm}$ and reduce machining time to 5 minutes. It was noted more smooth machining, much less vibration and better surface quality by reducing the height of scallops. After 20 workpieces machining proposed end mill kept possibility to work: spalling and chipping on the cutting edge is not detected. So, further increase of the cutting feed is impractical due to low rigidity of the technological system.

\section{Summary}

Thus, the effectiveness of the proposed end mill in the machine parts production, in particular, for complex spatial form of difficult-to-cut materials, which often are used in high-tech sectors of the industry was experimentally validated

\section{References}

1. Sandvik Coromant Company.

http://www.sandvik.coromant.com/en-

gb/knowledge/general_turning/selection-of-

inserts/geometry-information/wiper-inserts.

2. A.V. Khramov, E.N. Leksin, and I.V. Semdyakin, $R F$ Patent 145350 (2014) 